Journal of Systems Science and Information

Feb., 2017, Vol. 5, No. 1, pp. 34-47

DOI: $10.21078 /$ JSSI-2017-034-14

\title{
Study on the Transmission-Mechanism of International Factors Influencing Chinese Price Level
}

\author{
Menggen CHEN \\ School of Statistics, Beijing Normal University, Beijing 100875, China \\ E-mail: cmg2100@126.com \\ Decai YIN \\ School of Statistics, Beijing Normal University, Beijing 100875, China
}

\begin{abstract}
After the reform and opening, the economic relationship between China and the world is strengthened heavily. Theoretically, international factors have impact on the domestic general price level through a set of channels. This paper employed a sample including monthly data of five representative indicators, to explore the influence of international factors on Chinese price level. The empirical results showed that there is an obvious lag for Chinese CPI reacting to international shocks, while the PPI reacts immediately. The impact of international factors on Chinese CPI and PPI usually lasts 12 months at least and they always exhibit a different transmission mechanism for international shocks. Besides, a further study revealed that some structure-breakpoints in the influence mechanism of international factors exist, and great changes of the impact direction and significance for different factors have taken place in the subsample periods.
\end{abstract}

Keywords international factors; price level; transmission-effect; mechanism-switch

\section{Introduction}

Price is an important indicator in all economies. Theoretically, price level of a country is determined by many complicated factors. Under the background of globalization, when a closed economy opens to the world, the general price level will be affected by both domestic factors and international factors. After the reform and opening, the influence of international economic situation on Chinese economic development became more and more strong.

In 2001, China entered the WTO and then joined the big family of world economy. Now, China has been the second largest economy and plays a significant role in the global finance and investment, as well as the international trade. The capital flow between China and the rest of the world is very frequent. The domestic production and consumption is tightly linked to the international markets. Therefore, international inflation may have a great impact on the general price level of China and it is meaningful to explore the effect of international factors on the price level of a country. This paper intends to deal with the influence of international factors on the domestic price of China and investigate the transmission mechanism of this effect.

Received December 4, 2015, accepted January 7, 2016

Supported by Project of National Social Science Fund of China (14ZDA047, 13AZD086), Humanities and Social Science Project of the Ministry of Education (13YJA630005) and the Fundamental Research Funds for the Central Universities (2012WZD02) 


\section{Theory and Literature Review}

In a closed economy, let $M$ denote the quantity of currency at a period, $V$ and $T$ denote the velocity of currency and the quantity of goods. Then, price level $P$ could be expressed as $P=M V / T$, which means $P$ depending on $M, V$ and $T^{[1]}$. The Swedish school put forward a famous international imported inflation model: $I=I_{w}+A_{s}\left(K_{P}-K_{S}\right)$, where $I$ and $I_{w}$ denote domestic and international rate of inflation respectively, and $K_{P}$ and $K_{S}$ respectively denote labor productivity of sectors which closely link to the world economy and that of sectors which don't link to the world economy. In this equation, $A_{s}$ represents the share of those sectors which are not tied to the world economy in the whole economy. This means that the inflation rate is influenced by three factors: world inflation, labor productivity difference between open sectors and non-open sectors, and the share of non-open sectors make-up in the economy. In an open country, all activities are closely linked to the world economy. In macroeconomics, the Balassa-Samuelson model early explored the comparison of international price level. Based on the hypothesis of productivity, the fluctuation of international price will lead to changes in domestic price level through a set of transmission mechanisms and the price level of high income countries usually is higher ${ }^{[2,3]}$.

Since 1990s, fast globalization has led to a convergence of international price levels. For example, corresponding with the increasing openness during European integration process, price dispersion declined across countries ${ }^{[4]}$. With extended Phillips curve, the empirical results of Borio and Filardo ${ }^{[5]}$ indicated that the linkage between the inflation of OECD countries and the domestic output gap is becoming weaker, but the linkage between the inflation and global factors is becoming stronger. Keller and Shiue ${ }^{[6]}$ found that enhancement in the integration of international markets has corresponded with decreasing prices and markets integration is positively associated with price convergence due to the suppliers' competition and the scaleeconomy effect. Tang ${ }^{[7]}$ pointed out that globalization promotes international price convergence while price dispersion may exist for a long time due to quality differentiation, search cost and pricing behavior of multinational firms. Notably, the result of Ciccarelli and Mojon ${ }^{[8]}$ found that inflation of industrialized countries has been almost a global inflation phenomenon. The inflation rates of 22 OECD countries have a common factor that alone accounts for nearly 70 percent of their variance and the co-movement of inflation largely comes from common shocks. With the sample of India, Joshi and Acharya ${ }^{[9]}$ revealed that trade openness has a significant contribution to decrease the inflation, and since 1989 this relationship has grown stronger when the trade liberalization started to show macroeconomic effects in terms of structural break.

Many scholars explored the reasons for Chinese price fluctuation from the domestic perspective. For example, Cheng, et al. ${ }^{[10]}$ investigated the influence of domestic macroeconomic variables on Chinese price level and found that industrial value-added, investment, consumption, imports and exports, $M_{1}$ and $M_{2}$ all Granger cause CPI. Some other researchers analyzed the fluctuation reasons for Chinese general price from the international perspective. Lin and Wang ${ }^{[11]}$ studied the influence of energy price on Chinese price level using an input-output price impact model. With the Phillips curve including global factors, $\mathrm{Li}^{[12]}$ suggested that the output gap of OECD, import price index and oil price have a significant effect on Chinese general price level. Additionally, $\mathrm{He}^{[13]}$ investigated the relationship between international factors and 
Chinese inflation, and showed that international oil price and the effective rate of US federal fund could provide some extra information to predict Chinese inflation.

\section{Methodology}

About the international transmission of price shocks, there are some classic theories in economics, such as the Nordic model, Dornbusch model, Mundell-Fleming model and Taylor's monetary endogenous principle ${ }^{[14]}$. Theoreticallyinternational factors can influence domestic price level through the channels of international trade, balance of international payment, foreign exchange, international capital flow and international labor flow. Generally, because high barriers or strict entry permissions for labor mobility exist and changes in labor cost are very slow, the influence of labor flow on the price level of a country is relatively slow and insignificant. Under the standard assumption in economics, capital is mobile across sectors and countries whereas labor is only mobile across sectors ${ }^{[15]}$. Therefore, price shocks are usually transmitted to the related countries through international trade, foreign exchange market, balance of international payments and international capital flow ${ }^{[16]}$.

Based on the above transmission mechanisms, this study intends to investigate the influence of international factors on Chinese general price through international commodity price, international capital-flow and exchange rate, international trade and international financial markets etc. Moreover, due to the special importance of energy, international oil price is considered as an important factor. Chinese price level is represented by consumer price index (CPI) and producer price index (PPI), and international factors are represented by the following five indicators: NYSE Light Crude Oil Future Price (PF), U.S. Dollar Index (USDX), Baltic Dry Index (BDI), CRB Comprehensive Future Index (CRB) and Dow Jones Industrial Average Index (DJI).

The impulse response function and variance decomposition are employed to explore the transmission mechanism through which international factors influence Chinese general price level. In the VAR model, a shock to the $i$ th variable will not only directly affect the $i$ th variable, but also affect other endogenous variables through the dynamic structure of VAR model. The $\operatorname{VAR}(p)$ could be shown as follows:

$$
y_{t}=A_{1} y_{t-1}+A_{2} y_{t-2}+\cdots+A_{p} y_{t-p}+\varepsilon_{t} .
$$

In this equation, $y_{t}$ is a $k$-dimension endogenous vector and $\varepsilon_{t}$ is a multivariate sequence of stochastic error with covariance matrix $\Omega$. The $\operatorname{VMA}(\infty)$ model of $y_{t}$ could be written as

$$
y_{t}=\left(\psi_{0} I+\psi_{1} L+\psi_{2} L^{2}+\cdots\right) \varepsilon_{t} .
$$

Because $\operatorname{VAR}(p)$ model is invertible, the coefficients could be used to estimate the VMA model. Given $\psi_{q}=\left(\psi_{q, i j}\right), q=1,2, \cdots$, the $i$ th variable in $y$ could be written as

$$
y_{i t}=\sum_{j=1}^{k}\left(\psi_{0, i j} \varepsilon_{j t}+\psi_{1, i j} \varepsilon_{j t-1}+\psi_{2, i j} \varepsilon_{j t-2}+\psi_{3, i j} \varepsilon_{j t-3}+\cdots\right) .
$$

Following Equation (3), the impulse response function depicts the impact of a one-off shock to stochastic error on the current and future values of endogenous variables. Usually, the 
response function of $y_{i}$ resulting from the shock to $y_{j}$ could be written as

$$
\psi_{0, i j}, \psi_{1, i j}, \psi_{2, i j}, \psi_{3, i j}, \cdots
$$

In the method of variance decomposition, changes in endogenous variables could be decomposed into shocks on the components of VAR system. So the variance decomposition shows the relative importance of stochastic error influencing variables in VAR and reveals the order of importance of stochastic error affecting variables in VAR. The items in parentheses in Equation (3) are the sum of all impacts of $\varepsilon_{j}$ on $y_{i}$ and the variance of $y_{i t}$ could be calculated as

$$
\operatorname{var}\left(y_{i t}\right)=\sum_{j=1}^{k}\left\{\sum_{q=0}^{\infty}\left(\psi_{q, i j}\right)^{2} \sigma_{j j}\right\} .
$$

Generally, the var $\left(y_{i t}\right)$ could be decomposed into $k$ unrelated effects, an index (called relative variance contribution, RVC) is defined to analyze the contributions of error terms to the variance of $y_{i t}$, which is calculated as

$$
\operatorname{RVC}_{j \rightarrow i}(s)=\frac{\sum_{q=0}^{s-1}\left(\psi_{q, i j}\right)^{2} \sigma_{j j}}{\sum_{j=1}^{k}\left\{\sum_{q=0}^{s-1}\left(\psi_{q, i j}\right)^{2} \sigma_{j j}\right\}}, \quad i, j=1,2, \cdots, k .
$$

According to Equation (5), the bigger $\mathrm{RVC}_{j \rightarrow i}(s)$ is, the stronger the impact of $j$ th variable on $i$ th variable is; while the smaller $\operatorname{RVC}_{j \rightarrow i}(s)$ is, the weaker the impact of $j$ th variable on $i$ th variable is.

Additionally, in order to comprehensively investigate the influence of different factors on Chinese price level and the structural changes of transmission-mechanism, the following model is estimated:

$$
I_{t}=c+\alpha \cdot \mathrm{PF}_{t}+\beta \cdot \mathrm{USDX}_{t}+\varphi \cdot \mathrm{BDI}_{t}+\lambda \cdot \mathrm{CRB}_{t}+\delta \cdot \mathrm{DJI}_{t}+\varepsilon_{t},
$$

where $I_{t}$ denotes CPI or PPI at period $t$. The monthly data for CPI and PPI are collected from China Statistical Yearbook, and the monthly data for PF, USDX, BDI, CRB and DJI are got from Bloomberg system. Totally 191 observations for PPI are obtained ranging from January 1997 to November 2012 and 227 observations for rest variables ranging from January 1994 to November 2012. All of the sample data are standardized.

\section{Empirical Study}

\subsection{Preliminary Analysis}

Table 1 reports the correlation coefficients of the sample data. Chinese CPI is negatively associated with USDX and DJI, and positively associated with PF, CRB and BDI. The absolute value of correlation coefficient between CPI and DJI is the maximum, and that between CPI and BDI is the minimum. Chinese PPI is negatively associated with USDX, and positively associated with other variables. The absolute value of coefficients is between 0.41 and 0.52 and very close to each other. The absolute value of correlation coefficient between PPI and BDI is the maximum while that between PPI and DJI is the minimum. According to these results, the correlation between PPI and international factors is much higher than that between CPI and 
international factors. Moreover, CPI is positively related to PPI and the correlation coefficient between them is 0.7506; USDX is negatively associated with other variables; PF is positively associated with CRB and the correlation coefficient is 0.9374 , so they exhibit relative strong substitutability for each other.

Table 1 Correlation Coefficients of the Sample

\begin{tabular}{cccccccc}
\hline Variable & CPI & PPI & PF & USDX & CRB & BDI & DJI \\
\hline CPI & 1.0000 & & & & & & \\
PPI & 0.7506 & 1.0000 & & & & & \\
PF & 0.1258 & 0.4837 & 1.0000 & & & & \\
USDX & -0.3141 & -0.4272 & -0.6998 & 1.0000 & & & \\
CRB & 0.1904 & 0.5007 & 0.9374 & -0.6290 & 1.0000 & & \\
BDI & 0.0678 & 0.5140 & 0.4680 & -0.4787 & 0.3200 & 1.0000 & \\
DJI & -0.6121 & 0.4107 & 0.6897 & -0.1630 & 0.7191 & 0.4034 & 1.0000 \\
\hline
\end{tabular}

The Granger test is employed to study the causality and test the direction of causality between two variables, in order to judge the predicting effect of different factors on CPI and PPI. The Akaike and Schwarz information criterion are used to determine the appropriate lag length. The results suggest that PF, CRB and DJI Granger cause CPI; USDX and BDI don't Granger cause CPI. Especially, CPI Granger causes PF and BDI. On the contrary, PF, USDX, CRB and BDI Granger cause PPI, but DJI doesn't Granger cause PPI. Especially, PPI Granger causes only USDX.

\subsection{Analysis on Transmission-Effect}

According to impulse response function, when exerting a unit standard variance shock to a variable in VAR at period 1, all variables in the VAR system will respond in the subsequent periods. Figure 1 shows the accumulated response in the first 12 periods.

The analysis on the accumulated response of CPI found the following characteristics. First, from the perspective of reaction time, VAR system doesn't react immediately to innovations. The reaction of CPI to PF shocks lagged about 3 months, while that to USDX shocks lagged about 2 months. The reaction of CPI to CRB shock lagged about 1 month, which is small at first and then turns to significant reaction. Additionally, the reaction of CPI to BDI shocks lagged 3 months. Chinese CPI has a quick reaction to DJI shocks and responds at the subsequent periods, which shows that the influence of international financial market transmits quickly. Second, from the perspective of influence persistence, the reaction of VAR system to innovations shows no immediate convergence. Generally, the reaction will last 12 months at least and the shocks are digested gradually. Third, from the perspective of influence magnitude, a shock to variables in VAR system leads to gradual reaction of CPI, and the reaction usually reaches the maximum value at period 6th 9th. However, the reaction of CPI to different shocks varies greatly and exhibits no obvious regularity. Fourth, from the perspective of reaction direction, CPI positively reacts to shocks from PF and DJI and negatively reacts to the shocks from USDX. However, CPI has a positive reaction to shocks from CRB and BDI at first and then the reaction turns negative. Fifth, from the perspective of transmission pattern, the mechanism 
of shock transmission varies obviously for different variables. The transmission of shocks from PF, USDX and DJI are similar and exhibit a mode of enhancing on the same direction. The transmission mechanism of shocks from CRB and BDI is similar and shows a common feature of repeated correction mode, i.e., the positive reaction of CPI begins small and turns larger, but then the impact becomes smaller too until it exhibits a reversal correction at last. In other words, the influence of oil price and international financial market on Chinese CPI exhibits a positively enhancing mode, but the effect of U.S dollar exchange rate exhibits a negatively enhancing mode. This conclusion is consistent with economic theory. However, the effect of international commodity price and international shipping price on Chinese CPI exhibits a positively enhancing mode at first and then shows a negatively enhancing mode. In fact, the rise of these two factors directly lead to a rise of consumption goods price in China to some extent, however, any too fast rise of price is harmful to economic growth and may result in government intervention. Therefore, it constrains the growth of final consumption demand and so the influence of these two factors on Chinese CPI becomes negative finally.

The analysis on the accumulated response of PPI found the following characteristics. First, from the perspective of reaction time, VAR system reacts immediately to innovations of all variables except for DJI. That is, PPI reacts to shocks from PF, USDX, CRB and BDI in the next period, but the reaction to shocks from DJI is insignificant until period 4th. Therefore, the reaction of Chinese PPI to international factors is more sensitive than that of CPI. Second, from the perspective of influence persistence, the reaction of PPI to innovations also shows no immediate convergence. Generally, the reaction will last 12 months at least and the shocks are digested gradually too. Third, from the perspective of influence magnitude, the reaction of PPI to shocks of VAR system exhibits a process of gradual evolution. The reaction to shocks from USDX reaches the maximum value at period 8th, and the reaction to shocks from CRB, BDI and DJI reaches the maximum values at period 5th. And compared to CPI, the influence of international factors on PPI is much stronger. Fourth, from the perspective of reaction direction, PPI shows a continuously positive reaction to shocks from $\mathrm{PF}, \mathrm{CRB}$ and BDI, while a continuously negative reaction to shocks from USDX. However, PPI shows a negative reaction to shocks from DJI in the first two periods, and then turns positive. Fifth, from the perspective of transmission mechanism, the modes of transmission of shocks vary greatly for different variables. The patterns of PF, USDX, CRB and BDI are very similar and the reaction converges after the expansion at first. But PPI exhibits a negative reaction to shocks from DJI at first and then the reaction increases positively before coming to be stable gradually. This means that the influence of international financial market on Chinese upstream price is different from other international factors and the magnitude of influence is much smaller.

The variance decomposition can obtain relative importance of stochastic errors that influence variables in VAR system. Therefore, the importance of different factors in transmission mechanism of price shocks can be assessed. Table 2 reports the results of variance decomposition and main conclusions are as follows. 

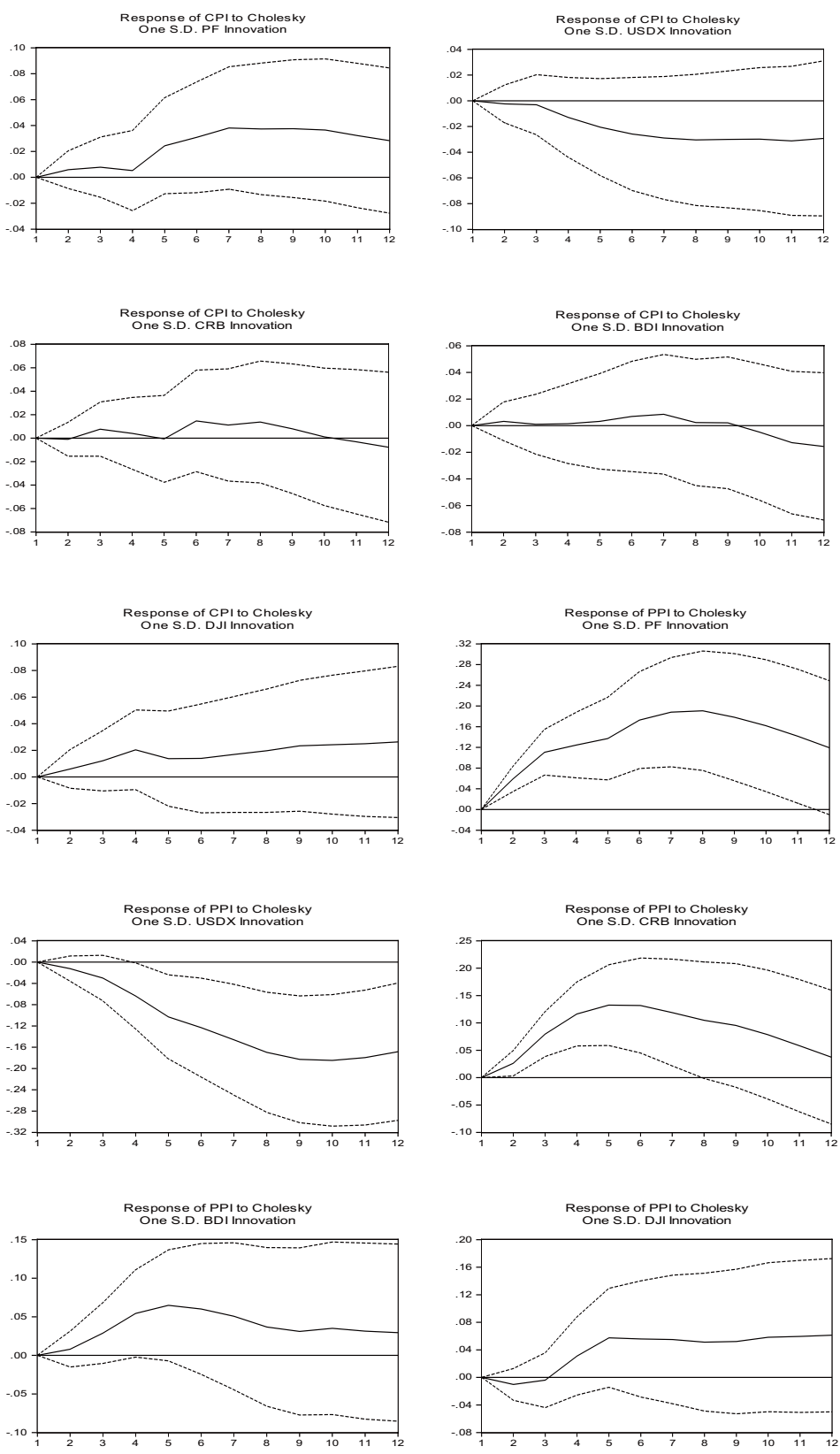

Figure 1 Analysis on impulse response of CPI and PPI 
Table 2 Analysis on variance decomposition of CPI and PPI

\begin{tabular}{|c|c|c|c|c|c|c|c|c|}
\hline Variable & Period & Standard Error & $\mathrm{CPI}$ & $\mathrm{PF}$ & USDX & CRB & BDI & DJI \\
\hline \multirow[t]{12}{*}{ CPI } & 1 & 0.1005 & 100.0000 & 0.0000 & 0.0000 & 0.0000 & 0.0000 & 0.0000 \\
\hline & 2 & 0.1599 & 99.6544 & 0.1366 & 0.0234 & 0.0041 & 0.0409 & 0.1407 \\
\hline & 3 & 0.2134 & 99.1949 & 0.2114 & 0.0342 & 0.1301 & 0.0255 & 0.4040 \\
\hline & 4 & 0.2598 & 98.5246 & 0.1827 & 0.2708 & 0.1120 & 0.0204 & 0.8895 \\
\hline & 5 & 0.3026 & 97.5865 & 0.7832 & 0.6585 & 0.0831 & 0.0266 & 0.8621 \\
\hline & 6 & 0.3433 & 96.3583 & 1.4197 & 1.0792 & 0.2465 & 0.0610 & 0.8354 \\
\hline & 7 & 0.3812 & 95.1387 & 2.1498 & 1.4528 & 0.2854 & 0.0995 & 0.8737 \\
\hline & 8 & 0.4144 & 94.1941 & 2.6325 & 1.7693 & 0.3510 & 0.0875 & 0.9655 \\
\hline & 9 & 0.4449 & 93.4850 & 2.9953 & 1.9912 & 0.3364 & 0.0782 & 1.1139 \\
\hline & 10 & 0.4720 & 92.9389 & 3.2600 & 2.1680 & 0.2993 & 0.0802 & 1.2535 \\
\hline & 11 & 0.4955 & 92.4466 & 3.3823 & 2.3644 & 0.2757 & 0.1390 & 1.3921 \\
\hline & 12 & 0.5154 & 92.0187 & 3.4278 & 2.5082 & 0.2777 & 0.2202 & 1.5474 \\
\hline \multicolumn{2}{|c|}{ Cholesky Ordering } & \multicolumn{7}{|c|}{ PPI PF USDX CRB BDI DJI } \\
\hline Variable & Period & Standard Error & PPI & $\mathrm{PF}$ & USDX & $\mathrm{CRB}$ & BDI & DJI \\
\hline \multirow[t]{12}{*}{ PPI } & 1 & 0.1464 & 100.0000 & 0.0000 & 0.0000 & 0.0000 & 0.0000 & 0.0000 \\
\hline & 2 & 0.2568 & 93.2264 & 5.2439 & 0.2277 & 1.0467 & 0.0976 & 0.1578 \\
\hline & 3 & 0.3692 & 81.8171 & 11.5088 & 0.7740 & 5.1540 & 0.6583 & 0.0878 \\
\hline & 4 & 0.4728 & 72.3771 & 13.9440 & 2.2786 & 9.1917 & 1.7209 & 0.4877 \\
\hline & 5 & 0.5651 & 63.6150 & 15.6398 & 4.9219 & 11.9278 & 2.5198 & 1.3756 \\
\hline & 6 & 0.6520 & 56.4175 & 18.7660 & 7.2663 & 13.0416 & 2.7422 & 1.7664 \\
\hline & 7 & 0.7298 & 50.8658 & 21.6187 & 9.8027 & 13.0633 & 2.6707 & 1.9789 \\
\hline & 8 & 0.7973 & 46.2269 & 23.8375 & 12.7386 & 12.6759 & 2.4507 & 2.0705 \\
\hline & 9 & 0.8531 & 42.3297 & 25.1816 & 15.7148 & 12.3205 & 2.2725 & 2.1809 \\
\hline & 10 & 0.8983 & 39.1621 & 25.9622 & 18.4036 & 11.8815 & 2.2019 & 2.3887 \\
\hline & 11 & 0.9332 & 36.7144 & 26.3594 & 20.7505 & 11.4012 & 2.1539 & 2.6205 \\
\hline & 12 & 0.9595 & 34.8580 & 26.4790 & 22.7090 & 10.9359 & 2.1314 & 2.8866 \\
\hline \multicolumn{2}{|c|}{ Cholesky Ordering } & \multicolumn{7}{|c|}{ PPI PF USDX CRB BDI DJI } \\
\hline
\end{tabular}

First, the largest share of CPI and PPI fluctuation is explained by its owner variance. According to the algorithm, the forecasting error at first step all comes from its owner innovation, that is, it accounts for all of the variance by itself. In the subsequent forecasts, the error will be affected by shocks from all variables in VAR system. The share that CPI itself accounts for is more than $92 \%$ in the first 12 periods. However, the share that PPI itself accounts for falls quickly from $93.23 \%$ at the 2 nd period to $50 \%$ at the 7 th period and $34.86 \%$ at the 12 th period. Obviously, the influence of international factors on Chinese PPI is more significant than that on Chinese CPI. Comparably speaking, the exogeneity of PPI is more significant while the endogeneity of CPI is more significant. This result is consistent with economic intuition that 
China has been an important processing trade economy in the world which imports a large number of raw materials and energy and exports industrial goods.

Second, the results of RVC indicator exhibit relatively great changes in the early stage for both CPI and PPI, and almost keep stable from the 10th period. During the whole periods, the forecasting error decomposition of CPI is relatively stable and the shares of different variables show very small changes over time. This reveals that the shares are not sensitive to prediction time and the relative importance of variables almost doesn't change over time. However, the prediction error decomposition of PPI changes greatly over time and the relative importance of different variables varies along with forecasting periods.

Third, the transmission-mechanism of shocks in VAR system is very different. According to the maximum contribution share to variance, the contribution shares of PF, USD, DJI and BDI to variance of CPI all reach their peaks at the 12th period, and account for $3.42 \%, 2.51 \%$, $1.55 \%$ and $0.22 \%$, respectively. However, the contribution share of CRB to variance of CPI reaches its peak at the 8 th period and accounts for $0.35 \%$. The contribution shares of PF, USD and DJI to variance of PPI reach their peaks at the 12th period and account for $26.48 \%$, $22.71 \%$ and $2.89 \%$, respectively. However, the contribution share of CRB to variance of PPI reaches its peak at the 7 th period accounting for $13.06 \%$, and the contribution share of BDI to variance of PPI reaches its peak at the 6th period accounting for $2.74 \%$. Therefore, there are differences in the transmission-mechanism of international factors influencing Chinese CPI and PPI, and both the magnitude and relative importance are different.

Fourth, the relative importance of different factors influencing Chinese price level is different over time. The shares of PF, USDX, BDI and DJI to variance of CPI show an upward trend in the first 12 periods. However, the share of CRB reaches the maximum at the 8th period and then declines. The shares of PF, USDX and DJI to variance of PPI show an upward trend too, while the shares of $\mathrm{CRB}$ and $\mathrm{BDI}$ reach the maximum at the 7th and 6th period respectively and then decline. It is worth to point out that the results of variance decomposition show that the influence of international commodity price on Chinese price level disappears very fast. This is inconsistent with the intuition inference to some extent. The reason might be that as an export-oriented economy China's price level is sensitive to international commodity price and make a fully reaction immediately to the fluctuation of commodity price. So, it only takes relatively shorter time to digest the shock from international commodity price.

\subsection{Analysis on Mechanism-Switch}

Equation (6) is estimated in order to comprehensively investigate the influence of international factors on Chinese general price and Table 3 shows the results. The regression of CPI on $\mathrm{PF}$, USDX, BDI, CRB and DJI obtains the following findings. The coefficient of PF is insignificantly positive while that of USDX is insignificantly negative. The coefficients of CRB and BDI are significantly positive at $5 \%$ and $1 \%$ level respectively and that of DJI is significantly negative at $1 \%$ level. Therefore, the international trade factors represented by CRB and BDI and the international financial market factor represented by DJI have significant impact on Chinese CPI. Intuitively, this is consistent with theoretical inference. However, the empirical results indicate that the impact of international oil price and U.S. dollar index on Chinese CPI isn't statistically significant and the reason might be as follows. On the one hand, international 
oil price and commodity price are good substitutions for each other, and the influence of oil prices on Chinese CPI might have been internalized into the effect of international commodity price. On the other hand, because the financial system especially capital and financial account of China has not yet been fully liberalized and there are some blocks hindering the price transmission, it is difficult for shocks of international monetary and exchange rate factors to form a direct and immediate influence on Chinese price.

Table 3 Results of regression model

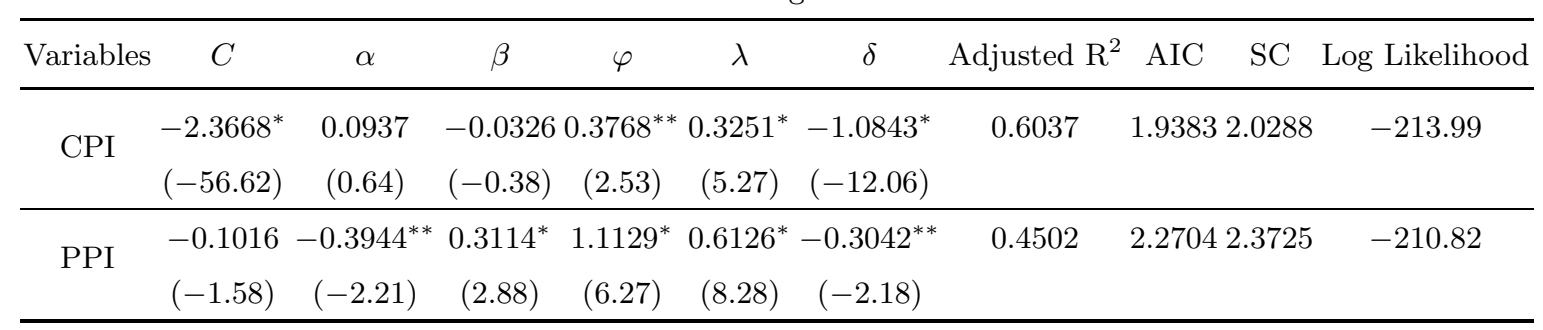

Notes: (.) is t-statistic; $*$ represents statistical significance at $1 \%$ level; $* *$ represents statistical significance at $5 \%$ level; $* * *$ represents statistical significance at $10 \%$ level.

Meanwhile, the regression of PPI on PF, USDX, BDI, CRB and DJI obtains the following findings. The coefficients of PF and DJI are significantly negative at $5 \%$ level, while the coefficients of USDX, CRB and BDI are significantly positive at $1 \%$ level. Obviously, the comprehensive analysis shows that international commodity price, international trade and exchange rate have a significantly positive influence on Chinese PPI, while international oil price and financial market have a significantly negative effect on PPI. The rise in international commodity price and shipping price will promote Chinese industrial product price. Because the rise in U.S. dollar index is usually resulted from the improvement of U.S. economy, so it's easy to understand that driven by the increase of U.S. market demands and Chinese PPI will go up too. About the estimated coefficients of PF and DJI, the reasons are as follows. On the one hand, international oil price and international commodity prices are substitutions for each other to some extent. On the other hand, international financial markets vary ceaselessly. PPI mainly depends on the real economy and whose behavior isn't so vulnerable to timely fluctuations in international financial markets. Therefore, the direct impact of international financial factors on Chinese PPI isn't significant.

Considering the changes in economic environment, the transmission mechanism of the influence of international factors on domestic price level may changes too. Since joining the WTO in 2001, the linkage between China and the world economy has been much closer and China has played an increasingly important role in international finance and trade. Moreover, 2008 international financial crisis has a profound effect on the world economy as well as Chinese economy. This study conducted Chow breakpoint test referring to January 2001 and January 2008 and the results obtain the following findings. For CPI, the values of F-statistic are 95.44 and 41.45 , and the corresponding $p$-values are both 0 . For PPI, the values of F-statistic are 6.25 and 4.44, and the corresponding $p$-values are 0 and 0.0003 respectively. Therefore, the results reveal that there do exist structural changes, which is consistent with the conclusion of Joshi and Acharya ${ }^{[9]}$. 
Table 4 Results of Chow test

\begin{tabular}{cccccc}
\hline \multirow{2}{*}{ Breakpoint } & \multicolumn{2}{c}{ CPI } & \multicolumn{2}{c}{ PPI } \\
\cline { 2 - 3 } \cline { 5 - 6 } & F-Statistic & Log Likelihood Ratio & & F-Statistic & Log Likelihood Ratio \\
\hline \multirow{2}{*}{2001.01} & $95.44^{*}$ & $294.73^{*}$ & & $6.25^{*}$ & $36.32^{*}$ \\
& {$[0.0000]$} & {$[0.0000]$} & {$[0.0000]$} & {$[0.0000]$} \\
\hline \multirow{2}{*}{2008.01} & $41.45^{*}$ & $174.47^{*}$ & $4.44^{*}$ & $26.52^{*}$ \\
& {$[0.0000]$} & {$[0.0000]$} & {$[0.0003]$} & {$[0.0002]$} \\
\hline
\end{tabular}

Notes: [.] represent corresponding $p$-value; ${ }^{*}$ represents statistical significance at $1 \%$ level.

So, the sample is divided into three subsamples with the above breakpoints and Equation (6) is estimated by the subsamples. The results are showed in Table 5 and there are significant changes in transmission mechanisms of shocks from international factors to Chinese CPI and PPI. For CPI, the main conclusions are found as follows. First, from the perspective of influence direction, the influence of USDX, CRB and DJI changes directions among the three subsamples. The coefficients of USDX are positive in subsample 1 and 3 while that is negative in subsample 2. The coefficients of CRB and DJI are negative in subsample 1, while those are positive in subsample 2 and 3. Meanwhile, the signs of coefficients of PF and BDI keep stable. This means that the direction of impact of international commodity price and Dow Jones industrial average index changes from negative to positive after China joining the WTO. The international exchange rate factor represented by USDX has a positive effect on Chinese CPI and a negative effect after China joining the WTO, while the influence returns to be positive after the outbreak of 2008 international financial crisis. The international oil price has a negative effect on Chinese CPI in the three subsamples, but the international trade has a positive effect on Chinese CPI among three stages. Second, from the perspective of significance, the coefficients of BDI are statistically significant in all three subsamples at $1 \%$ level, while the significance for the coefficients of other variables change through three subsamples. In subsample 1, the coefficient of PF is significant at $5 \%$ level, while the coefficients of USDX, CRB, BDI and DJI are significant at $1 \%$ level. In subsample 2 , only the coefficient of BDI is significant at $1 \%$ level, while others are all statistically insignificant. In subsample 3 , the coefficients of CRB and BDI are significant at $1 \%$ level, but others are insignificant.

For PPI, the main conclusions about the subsample regression are found as follows. First, from the perspective of influence direction, the influence of PF, USDX and BDI changes direction among the three subsamples. The coefficients of PF and USDX are positive in subsample 1 and 3 while those are negative in subsample 2. The coefficient of BDI is negative in subsample 1 while those are positive in subsample 2 and 3 . The coefficients of CRB and DJI keep positive and negative respectively in the three stages. This means that the influence direction of international shipping price on Chinese PPI changes from negative to positive after China joining the WTO. International oil price and exchange rate factors represented by U.S. dollar index have a positive effect on Chinese PPI in the first stage and have a negative effect after China joining the WTO, but the influence returns to be positive after the outbreak of 2008 international financial crisis. CRB has a positive influence on Chinese PPI in the three stages, 
while DJI has a negative influence on PPI at the same time. Second, from the perspective of significance, all coefficients of international factors change through the three stages. In subsample 1, the coefficient of CRB is significant at 1\% level, and those of PF and DJI are significant at $5 \%$ level; the coefficient of USDX is significant at $10 \%$ level and that of BDI is insignificant at all. In subsample 2, the coefficient of USDX is significant at $1 \%$ level, while those of PF and BDI are significant at 5\% level. However, the coefficient of DJI is significant at $10 \%$ level but that of CRB is insignificant at all. In subsample 3, the coefficients of BDI and CRB are significant at $1 \%$ level and that of USDX is significant at $5 \%$ level. However, the coefficients of $\mathrm{PF}$ and DJI are statistically insignificant. In all, the impacts of international factors on Chinese CPI and PPI exhibit obvious structural changes.

Table 5 Results of regression model for subsample

\begin{tabular}{ccccccccccc}
\hline Subsample & $C$ & $\alpha$ & $\beta$ & $\varphi$ & $\lambda$ & $\delta$ & Adjusted & AIC & $\begin{array}{c}\text { SC } \\
\text { Log Like- } \\
\text { lihood }\end{array}$ \\
\hline CPI & $-3.6303^{*}-1.0756^{* * *}$ & $0.5905^{*}$ & $-1.2068^{*}$ & $2.8120^{*}$ & $-1.1859^{*}$ & 0.8916 & 1.4438 & 1.6174 & -54.64 \\
$199401-200012$ & $(-7.11)$ & $(-1.69)$ & $(3.91)$ & $(-3.26)$ & $(6.51)$ & $(-8.94)$ & & & & \\
CPI & $-2.8565^{*}$ & -0.1616 & -0.0256 & 0.1323 & $0.2155^{*}$ & 0.0985 & 0.7374 & $-0.7686-0.5949$ & 38.28 \\
$200101-200712(-85.61)$ & $(-1.33)$ & $(-0.45)$ & $(0.69)$ & $(5.59)$ & $(1.46)$ & & & & \\
CPI & $-2.6730^{*}$ & -0.1848 & 0.1718 & $0.3239^{*}$ & $0.2224^{*}$ & 0.2248 & 0.6359 & 0.2104 & 0.4216 & -0.20 \\
$200801-201211(-14.61)$ & $(-1.00)$ & $(1.02)$ & $(3.73)$ & $(4.63)$ & $(1.62)$ & & & & \\
PPI & $2.0894^{*}$ & $0.9946^{* *}$ & $0.2163^{* * *}$ & -0.0715 & $3.4913^{*}$ & $-0.1639^{* *}$ & 0.9370 & $-0.5408-0.3069$ & 18.97 \\
$199701-200012$ & $(5.75)$ & $(2.13)$ & $(1.89)$ & $(-0.36)$ & $(7.36)$ & $(-2.43)$ & & & & \\
PPI & $0.4667^{*}$ & $-0.5804^{* * *}-0.4627^{*}$ & $1.0145^{* *}$ & 0.0597 & $-0.3089^{* * *}$ & 0.7057 & 1.0750 & 1.2487 & -39.15 \\
$200101-200712$ & $(5.56)$ & $(-1.90)$ & $(-3.30)$ & $(2.13)$ & $(0.61)$ & $(-1.83)$ & & & & \\
PPI & -0.0545 & 0.2669 & $1.5016^{* *}$ & $1.3387^{*}$ & $0.6991^{*}$ & -0.6095 & 0.4402 & 2.8671 & 3.0784 & -78.58 \\
$200801-201211$ & $(-0.07)$ & $(0.38)$ & $(2.37)$ & $(4.08)$ & $(3.85)$ & $(-1.16)$ & & & &
\end{tabular}

Notes: (.) is t-statistic; * represents statistical significance at $1 \%$ level; ** represents statistical significance at $5 \%$ level; $* * *$ represents statistical significance at $10 \%$ level.

\section{Conclusions and Policy Implications}

This paper employed a sample of monthly data including five representative indicators ranging from January 1994 to November 2012, and investigated the influence of international factors on Chinese price level as well as the structural changes of the shock transmission mechanism.

The empirical results come to the following conclusions. First, Chinese CPI doesn't react immediately to the innovation of international factors, while PPI reacts immediately. Second, both CPI and PPI haven't shown any rapid convergence to the innovations while the impact of international factors usually lasts 12 months at least. Third, there are obvious differences in the transmission-mechanism of international factor shocks between Chinese CPI and PPI. The reaction magnitude for different factors is inconsistent with each other as well as different relative importance over time. Fourth, CPI exhibits more obvious endogeneity, while PPI 
exhibits more obvious exogeneity. The influence of international factors on PPI is much more significant than that on CPI. Fifth, the influence of international commodity prices and international trade represented by shipping index and international financial market represented by Dow Jones industrial average index on Chinese CPI is statistically significant at the sample period, while the influence of international oil price and exchange rate represented by U.S. dollar index on Chinese CPI is statistically insignificant. Meanwhile, currency exchange rate, international commodity price and international trade have a significantly positive effect on Chinese PPI, but the international oil price and financial market factors have a significantly negative impact on Chinese PPI. Sixth, further studies showed that a structure change of the transmission-mechanism for international factors influencing Chinese price level has taken place during the sample period because the domestic and international economic environment greatly changed over time. There are significant changes in direction and significance for the impact of international factors after China joining the WTO and the outbreak of 2008 international financial crisis.

This study has some important policy implications. First, along with the economy openness, China plays a more and more prominent role in world markets and the impact of international factors on Chinese economy increases significantly. Especially, the influence of international commodity prices, international monetary market and exchange rate, global trade, and international financial situation on Chinese price level is becoming stronger. Therefore, to achieve the aim of price regulation and inflation control, both domestic and international factors should be taken into consideration. Second, due to the fact that international factors have different effects on Chinese general price over time, the government should pay more attention to the realistic transmission-mechanism through which international factors influence Chinese economy when macroeconomic policies are formulated. Third, the influence of international factors on Chinese PPI is more significant than that on Chinese CPI, and the reaction of PPI to international shocks is also faster than that of CPI. Therefore, when the changes of international market prices or financial market situations may bring shocks to Chinese price level, PPI especially the cost of enterprises should be got more attention at first. And then, appropriate measures should be taken to deal with the influence on domestic consumption prices.

\section{References}

[1] Mankiw N G. Macroeconomics. 7th Edition, Worth Publishers, 2009.

[2] Balassa B. The purchasing-power parity doctrine: A reappraisal. Journal of Political Economy, 1964, 72(6): 584-596.

[3] Samuelson P. Theoretical notes on trade problems. Review of Economics and Statistics, 1964, 64: 145-154.

[4] Rogers J H. Monetary union, price level convergence, and inflation: How close is Europe to the United States? Working paper, www.federalreserve.gov/ pubs/ifdp/, 2002.

[5] Borio C, Filardo A. Globalization and inflation: New cross-country evidence on the global determinants of domestic inflation. BIS Working paper, No.227, May, 2007.

[6] Keller W, Shiue C. Institutions, technology, and trade. NBER working paper 13913, http://www.nber.org/ papers/w13913, 2008.

[7] Tang J. Globalization and price dispersion: Evidence from U.S. trade flows. SSRN working paper, http://ssrn.com/, 2010. abstract=1572752.

[8] Ciccarelli M, Mojon B. Global inflation. SSRN working paper, http://ssrn.com/abstract_id =827245, 2008. 
[9] Joshi A R, Acharya D. Inflation and trade openness: Empirical investigation for India. IUP Journal of Monetary Economics, 2010, 8(1/2): 113-127.

[10] Cheng J H, Huang D L, Yang X G. Empirical study on the causes and conductive mechanism of price change in China. Statistical Research, 2008, 25(1): 30-34.

[11] Lin B Q, Wang F. Impact of energy price increase on general price level in China: A study based on input-output model and recursive SVAR model. Economic Research Journal, 2009(12): 66-79.

[12] Li H. Study on the influence of global factors on the inflation dynamics of China. Master Dissertation of Peking University, 2010.

[13] He Q Z. Are international factors helpful to predict Chinese inflation. Management World, 2012(11): 172173.

[14] Cheng Y. A study on factors affecting China's price fluctuation in open economy. Xiamen University, 2009.

[15] Fischer Christoph A, Hossfeld Oliver. A consistent set of multilateral productivity approach-based indicators of price competitiveness. ECB Working Paper No. 1706. http://ssrn.com/abstract=2464135, 2014.

[16] Gamber E N, Hung J H. Has the rise in globalization reduced U.S. inflation in the 1990s. Economic Inquiry, 2001, 39: 58-73. 